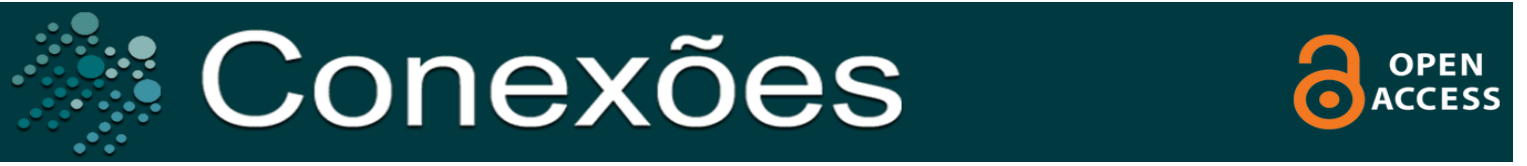

Artigo Original

\title{
A proficiência motora de crianças e a abordagem de ensino na educação física escolar: suscitando um debate
}

\author{
Motor proficiency in children and the teaching approach in school physical \\ education: raising a debate
}

\section{El dominio motor de los niños y el enfoque de enseñanza en educación física en la escuela: planteando un debate}

\author{
Bruno Adriano Rodrigues da Silva ${ }^{1}$ \\ Fábio Pinto Gonçalves dos Reis ${ }^{2}$ \\ Kleber Tuxen Carneiro ${ }^{2}$ \\ Alessandro Teodoro Bruzi ${ }^{2}$ \\ Ana Carolina da Silva ${ }^{2}$
}

\begin{abstract}
RESUMO
Objetivo: $O$ artigo analisa em paralelo a proficiência motora de crianças e a abordagem de ensino utilizada por um professor de Educação Física do $1^{\circ}$ e $5^{\circ}$ ano do ensino fundamental de uma escola pública municipal, localizada da região sul do estado de Minas Gerais. Método: Consideramos dois paradigmas para desenvolver a seguinte metodologia: i) teste TGMD-2 para avaliar a proficiência em habilidades motoras fundamentais e inferir a coordenação motora dos escolares; ii) observações sistemáticas e anotações em diário de campo das aulas de Educação Física destes mesmos escolares. Resultados: Observouse, por exemplo, que foi pouco frequente uma preocupação sistemática com a avaliação no interior da organização do trabalho docente. Conclusões: Concluímos que existe uma queda na proficiência motora dos escolares entre o $1^{\circ}$ e $5^{\circ}$ ano do ensino fundamental e que elementos básicos da organização do trabalho docente não foram verificados na abordagem de ensino, algo que suscita uma interface entre essas duas variáveis que compõem o cotidiano escolar da disciplina Educação Física.
\end{abstract}

Palavras-chave: Habilidades motoras. Ensino fundamental. Educação Física.

\footnotetext{
1 Universidade Federal do Estado do Rio de Janeiro, Departamento de Fundamentos da Educação, Rio de Janeiro - RJ, Brasil.

2 Universidade Federal de Lavras, Faculdade de Ciências da Saúde, Departamento de Educação Física, Lavras - MG, Brasil.
}

\section{Correspondência:}

Bruno Adriano Rodrigues da Silva. Universidade Federal do Estado do Rio de Janeiro, Av. Pasteur, 296, Urca, Rio de Janeiro - RJ, CEP 22290-240. Email: b.adriano rs@yahoo.com.br 


\section{ABSTRACT}

Objective: The article analyzes in parallel the motor proficiency a children and the teaching approach used by a Physical Education teacher from the 1st and 5th year of elementary school in a municipal public school, located in the southern region of the state of Minas Gerais. Method: We considered two paradigms of the science to develop the following methodology: i) TGMD-2 test to assess proficiency in fundamental motor skills and infer motor coordination of students; ii) systematic observations and notes in the field diary of the Physical Education classes of these same students. Results: It was observed, for example, that there wasn't usually a systematic concern with an evaluation within the teaching work organization. Conclusions: We conclude that there is a drop in the motor proficiency of students between the 1st and 5th year of elementary school and that basic elements of the organization of teaching work were not verified in the teaching approach, something that raises an interface between these two variables that make up the school routine Physical Education.

Keywords: Motor skills. Elemnetary school. Physical Education.

\section{RESUMEN}

Objetivo: El artículo analiza en paralelo la competencia motriz de los niños y el enfoque de enseñanza utilizado por un maestro de Educación Física del primer y quinto año de la escuela primaria en una escuela pública municipal, ubicada en la región sur del estado de Minas Gerais. Método: Consideramos dos paradigmas para desarrollar la siguiente metodología: i) prueba TGMD-2 para evaluar el dominio de las habilidades motoras fundamentales e inferir la coordinación motora de los estudiantes; ii) observaciones sistemáticas y notas en el diario de campo de las clases de Educación Física de estos mismos estudiantes. Resultados: Se observó, por ejemplo, que era poco común una preocupación sistemática por la evaluación dentro de la organización del trabajo docente. Conclusiones: Concluimos que hay una caída en la competencia motriz de los estudiantes entre el $1^{\circ}$ y $5^{\circ}$ año de la escuela primaria y que los elementos básicos de la organización del trabajo docente no se verificaron en el enfoque de enseñanza, algo que plantea una interfaz entre estas dos variables que conforman la rutina escolar Educación Física.

Palabras Clave: Habilidades motoras. Escuela primaria. Educación Física. 


\section{INTRODUÇÃO}

Este artigo resulta de pesquisas científicas desenvolvidas em um projeto de extensão vinculado a uma universidade pública federal, situada no sul do estado de Minas Gerais. Nele (lê-se no projeto), o ensino do esporte é desenvolvido por discentes dos cursos de bacharelado e licenciatura em Educação Física, sob a supervisão de um docente da aludida instituição, sendo realizado no turno oposto ao regular de 17 crianças do $1^{0}$ ano do ensino fundamental, com idade variando entre 6 e 7 anos, e 18 do $5^{\circ}$ ano dos anos iniciais do Ensino Fundamental, cuja idade varia entre 10 e 12 anos.

Avaliamos a coordenação motora dos participantes - entende-se neste estudo por coordenação motora a interação harmoniosa e econômica dos sistemas musculoesquelético, nervoso e sensorial para a produção de ações cinéticas precisas e equilibradas - valendo-se do teste TGMD-2 que avaliou a proficiência em habilidades motoras fundamentais, medida por intermédio de análise estatística dos dados obtidos e o teste $U$ de Mann-Whitney para comparação entre os anos escolares e posteriormente entre os sexos (SCHILLING; KIPHARD, 1974; ULRICH, 2000). Observamos de forma sistemática, com registros num diário de campo, a fim de categorizar a abordagem de ensino utilizada pelo professor de Educação Física - por abordagem de ensino compreende-se a forma e acepção dada à organização do trabalho docente - junto às crianças envolvidas com o projeto de extensão durante as suas atividades curriculares na Educação Física (DARIDO, 2012; LUDKE; ANDRÉ, 1986, MINAYO, 2001).

Nesse sentido, o artigo analisou em paralelo a coordenação motora de crianças e a abordagem de ensino utilizada pelo professor de Educação Física com a finalidade de suscitar uma interface entre essas duas variáveis que compõem o cotidiano daquela disciplina na escola. Tal empreendimento científico se justifica em função do escasso número de trabalhos acadêmicos dedicados a suscitar a interface entre as variáveis supracitadas, visto que, via de regra, a literatura especializada analisa-as separadamente (MALDONADO; LIMONGELLI, 2014; FERNANDES et al., 2017; MALDONADO; SILVA, 2018).

A título de informação, a organização do artigo dar-se-á em três momentos, sendo que no primeiro faz-se um debate de ordem epistemológica, em seguida descrevem-se as metodologias, para posteriormente se apresentar e discutir os dados de pesquisa à luz da literatura pertinente. Ao final têm-se as considerações finais.

\section{Dimensão ePISTEMOLÓGICA dA PESQUISA}

As pesquisas expostas neste artigo assentam-se sob dois paradigmas distintos: as Ciências da Vida (entre elas Saúde e Biológicas) e as Humanidades (em especial, Humanas e Sociais aplicadas). Thomas Khun (2006) ao 
caracterizar "paradigmas" afirma que eles são: "[...] as realizações científicas universalmente reconhecidas que, durante algum tempo, fornecem problemas e soluções modelares para uma comunidade de praticantes de uma ciência" (KUNH, 2006, p. 13). Fazer uso de um "paradigma", na acepção deste autor, significa para o cientista, escolher um marcador e nele transitar.

No âmbito da Educação Física, integrante de uma área (21) das Ciências da Saúde, normalmente estes paradigmas pouco dialogam, por efeito, procedimentos de pesquisa deles oriundos também seguem essa tendência, algo que, inclusive, já foi debatido pela literatura científica especializada (BRACHT, 2000; TANI, 2008; CARNEIRO et al., 2016; MANUEL, 2016; CARNEIRO et al., 2019; HALLAL; MELO, 2017). Porém, antes de descrevermos a metodologia, precisamos responder duas indagações relativas à Educação Física: por que esses paradigmas raramente se comunicam? Não obstante, quais são os fundamentos deles?

Historicamente, conforme evidenciam as pesquisas desenvolvidas no âmbito da Educação Física, esta disciplina vinculada à instituição escolar em nosso país desde o século XIX foi fundamentalmente orientada pela Medicina e pela Pedagogia. Na primeira, por intermédio da Higiene, uma ideologia que prospectava a assepsia nas relações sociais estabelecidas nos centros urbanos em formação, caso do Rio de Janeiro, por exemplo, que foi sede da família real portuguesa e primeira capital da república ao longo daquele século; pela Pedagogia, ao sistematizar uma disciplina escolar responsável por desenvolver procedimentos, normalmente ginásticos, que direcionavam os comportamentos e modelavam uma visão funcionalista (Biológica) do corpo humano (PAIVA, 2004; SOARES, 2004; SILVA, 2004; CUNHA JUNIOR, 2003; COSTA et al., 2014; BRACHT, 1999; MAIA, 2000).

Ambas as perspectivas, assentavam-se sob o paradigma Positivista de ciência que delimitava suas ações e, por efeito, também demarcava aquilo que era afeito cientificamente falando à Educação Física. Contudo, o que apregoava o aludido paradigma? De acordo com o seu fundador, Auguste Comte (1986), pensador do século XIX, o caráter fundamental do que ele chamava de filosofia positiva era a compreensão dos fenômenos sujeitos às leis naturais, isto é, às leis invariáveis que eram descritas pela Biologia que partia do entendimento, altamente analisado (no sentido de repartido), de que por intermédio da observação seguida da predição, os fenômenos naturais entendidos como invariáveis poderiam ser explicados por um conjunto de modelos. De acordo com o referido autor:

[...] no estado positivo, o espírito humano, reconhecendo a impossibilidade de obter noções absolutas, renuncia a procurar a origem e o destino do universo, para preocupar-se unicamente em descobrir, graças ao uso bem combinado do raciocínio e da observação, suas leis efetivas, a saber, suas relações invariáveis de sucessão e similitude (COMTE, 1986, p. 4). 
Nesse caso, a dinâmica na Educação Física com suas regras definidas seguia o que era prescrito por esse modo de produção do conhecimento científico. O positivo, por sua vez, sujeito às leis gerais preditas pela Biologia, conformariam área do conhecimento, algo que, a partir da década de 1970, conforme anotam Hallal e Melo (2017), passa a ser questionado pelas mudanças ocorridas no próprio universo da ciência, mais organizado na esfera da política, em razão da expansão do ensino de pós-graduação no Brasil e do aumento do financiamento científico via órgãos de fomento (CNPq, CAPES, dentre outros). À Educação Física nesse contexto de mudanças coube também a sua própria "revolução" científica, conforme acepção de Khum (2006), momento no qual o paradigma predominante é substituído totalmente ou parcialmente por outro paradigma. Mas, afinal, se trata de qual paradigma?

Nessa "revolução" foram sobretudo as teorias críticas provenientes da Educação que tinham como pauta a função social da instituição escolar que mais interferiram. Derivadas do paradigma Marxista, produzido por Karl Marx e Friedrich Engels (autores do século XIX), o que estava posto nesse olhar era a função reprodutora das relações sociais capitalistas que a escola, em geral, e a Educação Física, em particular, desempenhavam na sociedade (BRACHT, 1999; GUIRALDELLI JUNIOR, 1991). Para esse paradigma as explicações da realidade que envolvia a instituição escolar deveriam considerar que:

[...] na produção social da sua vida os homens entram em determinadas relações, necessárias, independentes da sua vontade, relações de produção que correspondem a uma determinada etapa de desenvolvimento das suas forças produtivas materiais. A totalidade destas relações de produção forma a estrutura econômica da sociedade, a base real sobre a qual se ergue uma superestrutura jurídica e política, e à qual correspondem determinadas formas da consciência social. O modo de produção da vida material é que condiciona o processo da vida social, política e espiritual. Não é a consciência dos homens que os determina, mas, inversamente, o seu ser social que determina a sua consciência (MARX, 1975, p. 25).

À vista disso e respondendo de modo sintético a interrogação do início da seção - "por que esses paradigmas raramente se comunicam? E que paradigmas são esses?" -, pode-se dizer que isso ocorre em função de uma historicidade científica que acabara por valorizar uma acepção em detrimento da outra, por efeito demarcando politicamente a Educação Física, situada ao abrigo da grande área, Ciências da Saúde, que também integra um complexo sistema de relações com outras grandes áreas, tal como as próprias Humanas e Sociais aplicadas. Não se trata, portanto, da ausência de diálogo entre os paradigmas, tampouco de uma coexistência pacífica, mas sim de disputas por predominância científica que, em última análise, significam a demarcação política para desenvolvimento de um paradigma em vez de outro.

Esse quadro, assim como reconhecemos acima, no entanto, não inviabiliza uma atitude científica disposta a colocar em paralelo tais paradigmas, 
notadamente no que, porventura, eles podem explicar a respeito do ofício do professor de Educação Física no domínio de uma instituição escolar pública: o experimental do Positivismo, aqui entendido como forma de aferir proficiência em habilidades motoras (modelo biológico) dos alunos envolvidos no interior do supramencionado projeto de extensão; e aquilo que é estruturado pelos modos de produção capitalista, preenchidos pelas relações sociais que ocorrem em uma escola pública que, por efeito, cumpre uma função social no limite do município em que está situada, segundo o prisma do Marxismo. Doravante, vejamos a metodologia proposta.

\section{Metodologia}

Sob a lente do paradigma experimental (Positivismo) aplicou-se um procedimento de natureza quantitativa, a bateria de avaliação motora Test of Gross Motor Development, $2^{\circ}$ edição (TGMD-2) (ULRICH, 2000), composta pelos sub testes de locomoção e manipulação ou controle de objetos. No primeiro sub teste foram executadas as seguintes tarefas, correr, saltar em uma perna, saltar horizontalmente, saltar um obstáculo, deslizar e galopar; no segundo sub teste foram executadas as tarefas, rebater, pegar, quicar, arremessar, rolar e chutar. Tal procedimento tinha como objetivo avaliar o desempenho dos escolares quanto às suas habilidades motoras fundamentais e permitir inferir sobre a sua coordenação motora.

A coleta de dados ocorreu na quadra poliesportiva da escola, local em que os escolares foram instruídos verbalmente sobre o procedimento e, em seguida, uma demonstração das habilidades motoras que deveriam ser realizadas em cada sub teste foi realizada. Logo após cada criança realizou um ensaio e duas tentativas válidas para cada habilidade que foram filmadas para uma análise posterior, considerando entre 3 a 5 critérios específicos, fundamentados em padrões maduros de cada movimento. Os dados foram computados e o quociente motor de cada criança foi estimado, comparado aos valores normativos e relativizados por sexo e idade. Para a estatística dos dados obtidos utilizamos o software Biostat, contudo, como verificamos a não homogeneidade e homocedasticidade, optamos por uma análise não paramétrica. Para comparação em relação aos anos escolares e posteriormente entre os sexos, aplicou-se o teste $\mathrm{U}$ de Mann-Whitney. Tendo em vista as diferenças significativas entre os conjuntos de dados se adotou $\mathrm{p}<0,05$ (ULRICH, 2000).

Ao abrigo do paradigma Marxista seguiu-se um procedimento de natureza qualitativa que foi desenvolvido por intermédio da observação sistemática, com registros em um diário de campo, de 4 aulas ministradas por um professor de Educação Física no $1^{\circ}$ ano e 4 aulas no $5^{\circ}$ ano do Ensino Fundamental também na quadra poliesportiva da escola (LUDKE; ANDRÉ, 1986). Nessa observação consideramos os elementos pertinentes à abordagem de ensino utilizada pelo professor na organização do trabalho pedagógico (DARIDO, 2012) e dela extraímos categorias descritivas, tais como: planejamento, mecanismos 
disciplinares, habilidades motoras fundamentais, ênfase na dimensão procedimental do ensino, qualidade da infraestrutura e dos recursos materiais, nível de interesse dos alunos e avaliação. Cumpre informar que para tal nos baseamos nas indicações de Minayo (2001), para quem categorizar significa estabelecer classificações de forma preliminar e a partir da coleta de dados para fins de aproximação com a realidade cotejada.

Compete-nos informar que todos os requisitos éticos necessários ao desenvolvimento da pesquisa que ocorreu no segundo semestre de 2016 foram atendidos, conforme normativa do Comitê de Ética da instituição de origem: CAEE 74979117.5.0000.514; número do parecer 2.354.148.

\section{Resultados e Discussão}

Analisando os dados sobre a proficiência nas habilidades motoras fundamentais quando comparado primeiro e quinto ano (Figura 1), observamos diferença significativa $(U=0.00 ; p<0.0001)$. Já na comparação entre os sexos, essa diferença não foi identificada $(U=120.50 ; p<0.18)$ (Figura 2).

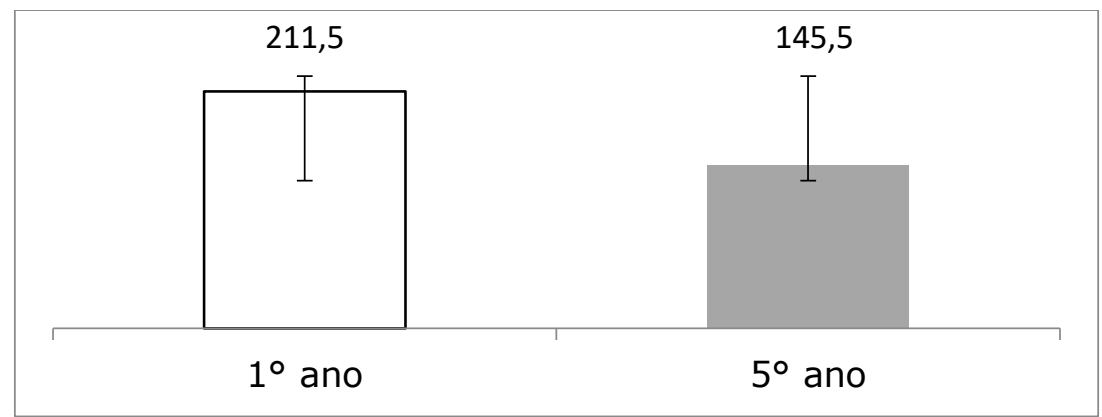

Figura 1 - Comparação da coordenação motora grossa entre as séries.

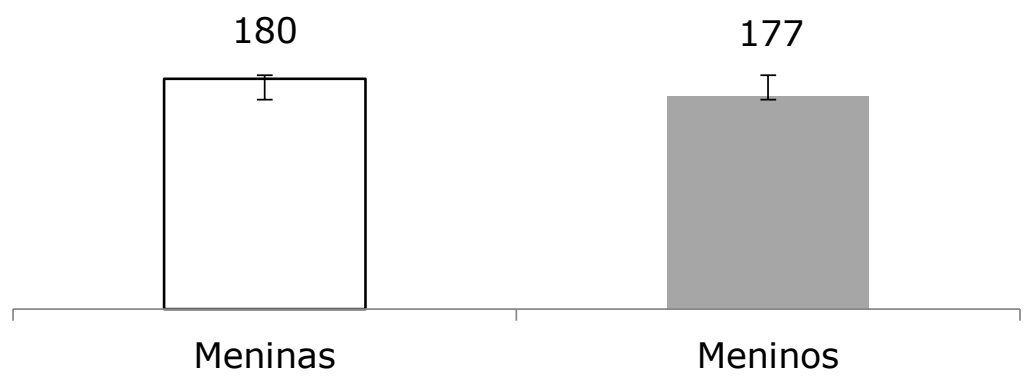

Figura 2 - Comparação da coordenação motora grossa entre os sexos.

$\mathrm{Na}$ classificação em relação ao quociente motor, as crianças do $1^{0}$ ano tiveram uma indicação de coordenação motora grossa média, sendo que àquelas do $5^{\circ}$ ano foram classificadas com coordenação motora aquém do estimado.

Quadro 1 - Classificação da coordenação motora dos participantes quanto ao quociente motor 


\begin{tabular}{|c|c|c|c|c|}
\hline Série & \multicolumn{2}{|c|}{$\mathbf{1}^{\circ}$ ano } & \multicolumn{2}{c|}{$\mathbf{5}^{\circ}$ ano } \\
\hline Sexo & Meninas & Meninos & Meninas & Meninos \\
\hline Pontuação & 109.5 & 102.0 & 70.5 & 75.0 \\
\hline $\begin{array}{c}\text { Avaliação } \\
\text { descritiva }\end{array}$ & Média & Média & Pobre & Pobre \\
\hline
\end{tabular}

Tais dados corroboram com os achados de Maia e Lopes (2007) que associam os piores resultados nos níveis de desempenho da coordenação motora às crianças mais velhas. Collet et al. (2008), ao considerar o mesmo fator idade, analisou a coordenação motora de 243 escolares com um intervalo de idade entre 8 e 14 anos e evidenciou a baixa na coordenação em 49,2\% dos escolares com idades entre 12 a 14 anos. Segundo Valdivia et al. (2008) as crianças com idades menores tendem a ser mais ativas no desenvolvimento de práticas corporais, em relação às crianças com idades mais avançadas, sendo essa uma possível justificativa para esses resultados.

Na comparação do desempenho da coordenação motora grossa entre os sexos, não encontramos diferenças significativas. Diferentemente dos dados de nosso estudo, contudo, Pelozin et al. (2009) constataram em uma amostra de 145 crianças, que, $48,4 \%$ dos meninos estavam com níveis elevados de coordenação motora, enquanto $44,8 \%$ das meninas apresentavam níveis mais baixos. Alinhado a essa verificação, Carminato (2010) concluiu que meninos apresentam maior proporção de normalidade da coordenação motora, após realizar um estudo na rede municipal de Cianorte, $\mathrm{PR}$, com 931 escolares.

Pois bem, ante ao exposto, engendrou-se um questionamento na direção de suscitar a discussão a partir da observação sistemática realizada das aulas de Educação Física: seria esta disciplina uma das variáveis responsável por esses resultados apresentados mediante as discussões, ao menos no que diz respeito à restrição de oportunidades educacionais por intermédio das práticas corporais nas aulas de Educação Física?

Para responder a essa indagação, primeiro, apresenta-se as categorias descritivas para depois discuti-las.

Quadro 2 - Síntese, por meio de categorias descritivas, das aulas de Educação Física

\begin{tabular}{|c|l|}
\hline Categoria & \multicolumn{1}{c|}{ Descrição } \\
\hline & $\begin{array}{l}\text { Foram identificados na observação das aulas procedimentos de } \\
\text { ensino que indicavam improvisação e ausência de planejamento, } \\
\text { tais como: repetições de procedimentos de ensino (exercícios), } \\
\text { Pão distinção entre os anos, ausência de alternativa em relação à } \\
\text { interferência de fatores ambientais, ausência de descrição das } \\
\text { aulas. }\end{array}$ \\
\hline
\end{tabular}




\begin{tabular}{|c|l|}
\hline $\begin{array}{c}\text { Mecanismos } \\
\text { disciplinares }\end{array}$ & $\begin{array}{l}\text { Identificou-se na observação das aulas a repetição de } \\
\text { procedimentos de ensino que possuíam o objetivo de controle } \\
\text { corporal, a saber: a organização em filas, atividades de ginástica } \\
\text { realizadas em círculo (alongamento) obrigatórias no início das } \\
\text { aulas e exercícios de volta à calma ao final. }\end{array}$ \\
\hline $\begin{array}{c}\text { Habilidades motoras } \\
\text { fundamentais }\end{array}$ & $\begin{array}{l}\text { Enfaticamente, verificou-se ao longo da observação das aulas, } \\
\text { tanto no 10, como no 50 ano, a utilização de procedimentos de } \\
\text { ensino visando o desenvolvimento de habilidades motoras } \\
\text { fundamentais, tais como, correr, saltar, manipulação de objetos, } \\
\text { em formato de "circuito motor". }\end{array}$ \\
\hline $\begin{array}{c}\text { Ênfase na dimensão } \\
\text { procedimental do } \\
\text { ensino }\end{array}$ & $\begin{array}{l}\text { Em todos os procedimentos de ensino adotados pelo professor, a } \\
\text { ênfase recaia sobre a técnica para o cumprimento das tarefas } \\
\text { motoras solicitadas. }\end{array}$ \\
\hline $\begin{array}{c}\text { Qualidade da } \\
\text { infraestrutura e dos } \\
\text { recursos materiais }\end{array}$ & $\begin{array}{l}\text { Na observação das aulas identificamos que o local era de } \\
\text { qualidade questionável, apesar de haver um espaço específico. Já } \\
\text { os materiais (bolas, cones, cordas bambolês, entre outros) } \\
\text { disponíveis para a prática da Educação Física eram em grande } \\
\text { medida escassos. }\end{array}$ \\
\hline $\begin{array}{c}\text { Nível de interesse } \\
\text { dos alunos }\end{array}$ & $\begin{array}{l}\text { Verificamos na observação de forma recorrente que os alunos } \\
\text { após alguns minutos desenvolvendo os procedimentos propostos } \\
\text { pelo professor perdiam o interesse e dispersavam. }\end{array}$ \\
\hline Avaliação & $\begin{array}{l}\text { Não se verificou procedimentos avaliativos propostos pelo } \\
\text { professor. }\end{array}$ \\
\hline
\end{tabular}

Refletindo a respeito do planejamento didático-pedagógico de um professor - algo que não se identificou na proposta de ensino analisada, vale sublinhar pode-se afirmar que ele é uma prática docente processual - uma espécie de marco referencial da organização do trabalho pedagógico - que envolve uma projeção de ações que serão adotadas pelo professor, na interação (e intervenção) com o contexto escolar para atingir os objetivos da instituição. A não utilização dessa sistematização incorre, por sua vez, no que alguns estudiosos denominam de "improvisação ou acaso", situação que compromete, de alguma maneira, os efeitos do ensino, por sua vez da aprendizagem, não sendo nenhuma hipérbole afirmar que afeta a função social da instituição escolar e oblitera o status do componente curricular Educação Física (GANDIN, 1991; KARLING, 1991; LIBÂNEO, 1994; GANDIN; CRUZ, 1995; VASCONCELLOS, 1995 apud BOSSLE, 2002).

O planejamento, ademais, é assunto recorrente em pesquisas sobre a organização do trabalho docente. Lopes et al. (2016) evidenciaram em um estudo na região nordeste do país que, em geral, professores de Educação Física entendem o planejamento como mecanismo de regulação por parte das instituições escolares e não como ação sistemática que possui uma determinada finalidade, sendo ela imprescindível para a prática docente. Amaral (2004), de igual modo, destaca o planejamento coletivo como forma de superação dos procedimentos de ensino entabulados por manuais, algo que aproxima os docentes da produção de saberes escolares conferindo virtude ao trabalho docente e à 
produção de sentido ao discente, por conseguinte, à Educação Física na condição de componente curricular.

Nesse contexto assistemático das aulas observadas também verificamos a utilização recorrente de mecanismos disciplinadores, contudo, não sabemos se decorrentes da ausência de planejamento ou se decorrentes de uma perspectiva militarista e utilitarista, muito comum à Educação Física brasileira desde o século XIX (OLIVEIRA, 2004). Também chama atenção, para além da abordagem em si, o desdobramento que tal procedimento sugere, mesmo que indiretamente, uma vez que ele limita o acesso e a compreensão das diferentes formas de desenvolvimento dos saberes relativos às práticas corporais historicamente construídas, tais como a ginástica, conforme já retratado na literatura específica (NEGRINE; GAUER, 1990; CESÁRIO, 2001).

Ainda nesse contexto de ensino assistemático também verificamos um conjunto de atividades voltadas para o desenvolvimento motor das crianças envolvidas com as aulas de Educação Física, tanto no $1^{\circ}$ ano, quanto no $5^{\circ}$ ano do Ensino Fundamental, realizadas pelo professor sem distinções. Em que pese tal tentativa, algumas fragilidades ficaram evidentes, notadamente em relação ao que caracteriza a abordagem desenvolvimentista no âmbito da Educação Física, a saber: o desenvolvimento fisiológico, motor, cognitivo e afetivo-social do indivíduo, considerando as suas etapas (maturação), a divisão em termos de habilidades motoras fundamentais e especializadas, bem como a própria solução de problemas motores pertinentes ao contexto onde as atividades são desenvolvidas (TANI et al., 1988; MANOEL, 1994; GOODWAY; BRANTA, 2003; NASCIMENTO et al., 2011).

Vale frisar que a primeira infância é a fase do desenvolvimento mais apropriada para a aquisição das habilidades motoras fundamentais (GOODWAY; BRANTA, 2003; GABBARD, 2000; HAYWOOD; GETCHELL, 2001; NASCIMENTO, 2011). Corolário a isso, no $1^{\circ}$ ano do ensino fundamental, no qual as crianças possuem, normalmente, entre 6 e 7 anos de idade, encontrar-se-iam próximas ao estágio maduro das habilidades motoras fundamentais. Nesse caso, seria importante conferir vivências práticas solicitando o uso de habilidades combinadas, procurando transitar para o desenvolvimento das habilidades motoras especializadas, por intermédio da realização de tarefas mais complexas e não apenas habilidades motoras descontextualizadas, conforme se constatou - ao menos no período pesquisado - ao longo das observações sistemáticas do trabalho pedagógico exercido pelo professor de Educação Física. Ademais, compete-nos ainda destacar que, no $5^{\circ}$ ano, os conteúdos ofertados e os procedimentos (motores) exigidos dever-se-iam ser ainda mais elaborados, combinando vivências esportivas com demandas funcionais do cotidiano das crianças.

Verificou-se ainda ao longo do período de observação sistemática das aulas, que as mesmas se restringiam à dimensão procedimental. Conjecturamos que isso tenha relação com a ausência de planejamento, tal como com a própria tradição desta disciplina escolar, uma vez que a técnica (esportiva em especial), o saber 
fazer, figura quase que exclusivamente como o seu objetivo (BRACHT, 2001; RODRIGUES; DARIDO, 2008; DARIDO; RANGEL, 2005).

Darido (2012) anota que a dimensão procedimental diz respeito àquilo que a criança também deve apreender em seu envolvimento com as práticas corporais, todavia, outras dimensões do conteúdo, conceitual e atitudinal, segundo esta autora, devem com ela guardar relações, granjeando assim, relevância à prática, justamente porque adjudicam sentido para o "o quê fazer" e sobre o "como ser" durante as experiências.

No que diz respeito aos efeitos da infraestrutura limitada da escola, bem como da escassez de materiais no desenvolvimento das aulas de Educação Física no $1^{\circ}$ e $5^{\circ}$ ano do Ensino Fundamental, pode-se afirmar de acordo com Tani et al. (2013) - em uma análise crítica sobre a Educação Física Escolar e o esporte de alto rendimento, em função da realização dos megaeventos esportivos no Brasil entre os anos de 2007 e 2016 - que o professor foi de fato afetado. Isto, contudo, deve ser previsto no planejamento docente e, por efeito, no desenvolvimento das atividades, algo que não verificamos durante a observação sistemática das aulas, como forma de mitigar tais impactos e garantir minimamente os espaços de aprendizagem das práticas corporais.

Ainda com base nas categorias descritas no quadro 2, em razão da observação sistemática, verificamos certo desinteresse das crianças envolvidas com a disciplina Educação Física, tanto no $1^{\circ}$ ano, quanto no $5^{\circ}$ ano. Darido (2004) glosa, em estudo abrangente feito com discentes da rede municipal de Rio Claro (SP), que há prevalência do desinteresse em relação às aulas de Educação Física por um conjunto de razões decorrentes das "fendas" que a legislação vigente apresenta, passando pelas experiências pregressas (sucesso ou exclusão) no interior desse componente curricular. A referida autora afirma ainda, que se trata de um processo que acompanha toda a trajetória escolar e ganha contornos mais efetivos no âmbito do Ensino Médio, algo que também é evidenciado no estudo etnográfico de Cesaro (2016) sobre o abandono das aulas de Educação Física por discentes nesta etapa do ensino.

O intrigante do cenário cotejado por este artigo refere-se ao fato de que, nos anos iniciais do Ensino Fundamental há forte adesão e entusiasmo - haja vista o "impulso lúdico" presente na cultura infantil, dentre outros fatores - em relação às aulas de Educação Física, de modo geral, um quadro dissidente daquele que verificamos durante a observação sistemática, cujo desinteresse, a baixa adesão e a conservação do entusiasmo durante as aulas foram evidenciados (CARNEIRO, 2012). Tal condição pode ser resultante, da própria abordagem de ensino utilizada pelo professor que, a depender da sua organização (ou da ausência dele), poderá potencializar o desinteresse por parte dos discentes, sobretudo, quando se desconsidera o contexto didático, isto é, o conjunto de procedimentos elaborados para ampliação das oportunidades escolares de modo equitativo (LIBÂNEO, 1994). 
E na qualidade de última categoria descritiva exposta no quadro 2, procurouse verificar quanto ao processo de avaliação pensado para aferir o trabalho pedagógico realizado, no entanto, ele não foi encontrado durante a observação sistemática. Não se trata, entretanto, de estigmatizar o professor de Educação Física, mas de sublinhar que, do ponto de vista político-pedagógico da instituição, existe algo fora de contexto que, supostamente, explica os motivos para não cumprimento de um requisito básico em qualquer processo educacional. De acordo com Luckesi (2000) a avaliação não é uma ação pontual, descontextualizada e desconexa dos processos cognitivos, sociais e culturais na qual o indivíduo está inserido, mas, sobremaneira, um espaço de construção coletiva em que a apropriação dos conteúdos nas suas três dimensões (procedimental, conceitual e atitudinal) é colocada em evidência, com vistas a aferir uma experiência formativa. A avaliação é, portanto, uma oportunidade de se aferir experiências de ensino e possibilidades de aprendizagem, observando "o esforço do aluno de aprender", tal e qual "o do professor de mudar suas práticas, caso os alunos apresentem dificuldades de aprendizagem" naquilo que diz respeito aos conteúdos da Educação Física (DARIDO, 2012, p. 131).

Clarividente que tais delimitações conceituais não se alinham com o panorama que verificamos na descrição da categoria avaliação. Aliás, parece destoar, em geral, com a própria delimitação conceitual das abordagens de ensino na Educação Física brasileira, conforme revela o estudo de Pereira (2019), cujo objetivo foi analisar tais abordagens e concluindo que apenas três apresentam uma preocupação sistemática com avaliação no interior da organização do trabalho docente. Não sem razão, trata-se de uma característica - reincidente, conquanto preocupante - do próprio campo educacional, uma vez que a avaliação ocupa uma "topografia periférica" na formação de professores, normalmente vinculadas à realização de provas e atribuição de notas (STIEG et al., 2018).

Doravante, após chegarmos ao fim da descrição e das discussões a respeito das categorias expostas no Quadro 2, passaremos às considerações finais.

\section{CONSIDERAÇÕES FINAIS}

O artigo analisou em paralelo a proficiência motora e a organização do trabalho pedagógico realizado no interior do componente curricular Educação Física em uma escola pública, como forma de suscitar uma interface entre essas duas variáveis. Nossas considerações, portanto, são constituídas com base em inferências da realidade cotejada, reiterando que a contextura da pesquisa deriva de uma atividade de extensão universitária, o que em alguma medida, engendrou certos limites ao estudo, ao mesmo tempo em que gerou uma atmosfera investigativa interessante, lançando luz para que outras conjecturas possam ser produzidas e perspectivas de investigação mais refinadas inauguradas.

A propositura heurística que exploramos nesse artigo - ao colocar em paralelo dois procedimentos metodológicos de pesquisa provenientes de dois 
paradigmas nos domínios da Educação Física, o Positivismo e o Marxismo - decorre de um movimento de superação histórica, na direção de ampliar um debate que ao longo dela (lê-se da história) foi apenas fortuito entre aqueles paradigmas. É, portanto, na fragilidade deste artigo que se encontra sua pujança, ao propor um debate sobre tais paradigmas antes de discorrer sobre a organização metodológica (procedimental) da pesquisa.

Os dados acerca da proficiência motora sinalizam uma queda no desempenho entre os alunos $1^{\circ}$ ano para os do $5^{\circ}$ ano do ensino fundamental. Um quadro que pode ser afetado por um conjunto de fatores relativos, conforme expusemos à luz da literatura pertinente, conquanto, também influenciado pelos limites pedagógicos identificados na abordagem de ensino a qual a pesquisa retratou.

Conforme analisamos, a abordagem do professor desconsiderou elementos fulcrais para a organização do trabalho pedagógico, a exemplo da ausência de planejamento, da não observância da progressão motora, ou mesmo a diferenciação de procedimentos concernentes ao desenvolvimento das práticas corporais entre diferentes anos do Ensino Fundamental, ao mesmo tempo em que recorreu à utilização de mecanismos disciplinadores, tolhendo vivências e escamoteando conteúdos pertinentes às práticas corporais. É bem verdade também que a infraestrutura da instituição escolar pouco colaborou com a organização do trabalho docente e isso potencializou, assim inferimos, o desinteresse das crianças envolvidas nas experiências escolares que, por serem restritivas, pouco proporcionavam a apropriação simbólica (cultural), quiçá, de natureza biológica. A ausência de procedimentos de avaliação daquelas experiências também foi um dado registrado, algo que acrescenta elementos a nossa análise.

Por certo, tratou-se de um exercício importante e desafiador, ao mesmo tempo em que se procurou realizá-lo com rigor e coerência, na expectativa de lançar rebento para a Educação Física, ao coadunar, mesmo que em paralelo, dois paradigmas, aproximando metodologias de pesquisa por intermédio de inferências feitas com base em literatura pertinente.

\section{NOTAS}

\section{CONFLITOS DE INTERESSE}

Os autores não têm conflitos de interesse, incluindo interesses financeiros específicos e relacionamentos e afiliações relevantes ao tema ou materiais discutidos no manuscrito.

\section{AUTORIA E COAUTORIA}

A autoria é responsável pelos conteúdos do texto. Os autores declaram que participaram de forma significativa na construção e formação desde estudo, tendo, enquanto autor, responsabilidade pública pelo conteúdo deste, pois, contribuíram 
diretamente para o conteúdo intelectual deste trabalho e satisfazem as exigências de autoria.

Bruno Adriano Rodrigues da Silva - Concepção e desenvolvimento (desde a ideia para a investigação ou artigo, criou a hipótese); Desenho metodológico (planejamento dos métodos para gerar os resultados); Supervisão (responsável pela organização e execução do projeto e da escrita do manuscrito); Coleta e tratamento dos dados (responsável pelos experimentos, pacientes, organização dos dados); Análise / interpretação (responsável pela análise estatística, avaliação e apresentação dos resultados); Levantamento da literatura (participou da pesquisa bibliográfica e levantamento de artigos); Redação (responsável por escrever uma parte substantiva do manuscrito); Revisão crítica (responsável pela revisão do conteúdo intelectual do manuscrito antes da apresentação final).

Fábio Pinto Gonçalves dos Reis - Concepção e desenvolvimento (desde a ideia para a investigação ou artigo, criou a hipótese); Desenho metodológico (planejamento dos métodos para gerar os resultados); Supervisão (responsável pela organização e execução do projeto e da escrita do manuscrito); Análise / interpretação (responsável pela análise estatística, avaliação e apresentação dos resultados); Levantamento da literatura (participou da pesquisa bibliográfica e levantamento de artigos); Redação (responsável por escrever uma parte substantiva do manuscrito); Revisão crítica (responsável pela revisão do conteúdo intelectual do manuscrito antes da apresentação final).

Kleber Tuxen Carneiro - Concepção e desenvolvimento (desde a ideia para a investigação ou artigo, criou a hipótese); Desenho metodológico (planejamento dos métodos para gerar os resultados); Supervisão (responsável pela organização e execução do projeto e da escrita do manuscrito); Análise / interpretação (responsável pela análise estatística, avaliação e apresentação dos resultados); Levantamento da literatura (participou da pesquisa bibliográfica e levantamento de artigos); Redação (responsável por escrever uma parte substantiva do manuscrito); Revisão crítica (responsável pela revisão do conteúdo intelectual do manuscrito antes da apresentação final).

Alessandro Teodoro Bruzi - Concepção e desenvolvimento (desde a ideia para a investigação ou artigo, criou a hipótese); Desenho metodológico (planejamento dos métodos para gerar os resultados); Supervisão (responsável pela organização e execução do projeto e da escrita do manuscrito); Coleta e tratamento dos dados (responsável pelos experimentos, pacientes, organização dos dados); Análise / interpretação (responsável pela análise estatística, avaliação e apresentação dos resultados); Levantamento da literatura (participou da pesquisa bibliográfica e levantamento de artigos); Redação (responsável por escrever uma parte substantiva do manuscrito); Revisão crítica (responsável pela revisão do conteúdo intelectual do manuscrito antes da apresentação final).

Ana Carolina da Silva - Concepção e desenvolvimento (desde a ideia para a investigação ou artigo, criou a hipótese); Desenho metodológico (planejamento dos métodos para gerar os resultados); Supervisão (responsável pela organização e execução do projeto e da escrita do manuscrito); Coleta e tratamento dos dados (responsável pelos experimentos, pacientes, organização dos dados); Análise / interpretação (responsável pela análise estatística, avaliação e apresentação dos resultados); Levantamento da literatura (participou da pesquisa bibliográfica e levantamento de artigos); Redação (responsável por escrever uma parte substantiva do manuscrito); Revisão crítica 
(responsável pela revisão do conteúdo intelectual do manuscrito antes da apresentação final).

\section{REFERÊNCIAS}

ALMEIDA, Roseane Soares. A ginástica na escola e na formação de professores. 2005. Tese (Doutorado em Educação) - Faculdade de Educação, Universidade Federal da Bahia, Salvador, 2005. Disponível em: http://www.repositorio.ufba.br/ri/handle/ri/11926. Acesso em: 07 ago. 2019.

AMARAL, Gislene Alves do. Planejamento de currículo na Educação Física: possibilidades de um projeto coletivo para as escolas públicas de Uberlândia/Minas Gerais. Movimento, Porto Alegre, v. 10, n. 11, p. 133-155, jan. 2004. Disponível em:

file:///C:/Users/Bruno\%20Adriano/AppData/Local/Packages/Microsoft.MicrosoftEdge 8we kyb3d8bbwe/TempState/Downloads/2829-9945-1-PB\%20(3).pdf. Acesso em: 07 ago. 2019.

BOSSLE, Fabiano. Planejamento de ensino na educação física - uma contribuição ao coletivo docente. Movimento, Porto Alegre, v. 8, n. 1, p. 31-39, dez. 2007. Disponível em: https://seer.ufrgs.br/Movimento/article/view/2635/1261. Acesso em: 07 ago. 2019.

BRACHT, Valter. Educação física \& ciência: cenas de um casamento (in)feliz. Revista Brasileira de Ciências do Esporte, v. 22, n. 1, p. 53-63, set., 2000. Disponível em: http://revista.cbce.org.br/index.php/RBCE/article/view/753/427. Acesso em: 07 ago. 2019.

BRACHT, Valter. A constituição das teorias pedagógicas da educação física. Caderno Cedes, Campinas, v. 19, n. 48, 1999. Disponível em:

http://www.scielo.br/pdf/ccedes/v19n48/v1948a05.pdf. Acesso em: 04 fev. 2020.

BRACHT, Valter. Saber e fazer pedagógicos: acerca da legitimidade da educação física como componente curricular. In: Francisco Eduardo Caparroz. (Org.). Educação Física Escolar: política, investigação e intervenção. Vitória: Proteoria, 2001. p. 67-79.

CARMINATO, Ricardo Alexandre. Desempenho motor de escolares através da bateria de teste KTK. 2010. Dissertação (Mestrado em Educação Física). Departamento de Educação Física, Universidade Federal do Paraná, Curitiba, 2010.

CARNEIRO, Kleber Tuxen. O jogo na Educação Física Escolar: as concepções dos professores. São Paulo: Phorte Editora, 2012.

CARNEIRO, Kleber Tüxen; ASSIS, Eliasaf Rodrigues de; BRONZATTO, Maurício. Da necessidade à negação: a percepção da crise epistemológica na Educação Física a partir da compreensão docente. Revista Brasileira de Ciência e Movimento, Brasília, v. 4, n. 4, p. 129-142, dez. 2016. Disponível em:

https://portalrevistas.ucb.br/index.php/RBCM/article/view/6825/pdf . Acesso em: 07 ago. 2019.

CARNEIRO, Kleber Tuxen; SILVA, Bruno Adriano Rodrigues; SANTOS, Bianca Stefany da Costa. O debate científico na Educação Física e os seus desdobramentos expressos nos trabalhos de conclusão de curso em uma universidade do estado de Minas Gerais. Corpoconsciência, Cuiabá, v. 23, n. 01, p. 25-37, abr. 2019. Disponível em: http://periodicoscientificos.ufmt.br/ojs/index.php/corpoconsciencia/article/view/7656/52 89. Acesso em: 07 ago. 2019.

CESÁRIO, Marliene. A organização do conhecimento da ginástica no currículo de formação inicial do profissional de Educação Física: realidade e possibilidades. 2001. Tese (Doutorado em Educação) - Faculdade de Educação, Universidade Federal de 
Pernambuco, Recife, 2001. Disponível em:

http://www.nuteses.temp.ufu.br/tde busca/processaPesquisa.php?pesqExecutada=2\&id =401\&listaDetalhes\%5B\%5D=401\&processar=Processar. Acesso em: 07 ago. 2019.

CESARO, Humberto Luiz. Abandono discente nas aulas de educação física do Ensino Médio: uma etnografia escolar na rede estadual do meio-oeste catarinense. 2016. Tese (Doutorado em Ciências do Movimento Humano), Escola Superior de Educação Física, Universidade Federal do Rio Grande do Sul, Porto Alegre, 2016. Disponível em: https://www.lume.ufrgs.br/bitstream/handle/10183/159121/001022445.pdf?sequence= 1. Acesso em: 07 ago. 2019.

COLLET, Carine; FOLLE, Alexandra; PEZOLIN, Fernanda; BOTTI, Marise; NASCIMENTO, Juarez Vieira do. Nível de coordenação motora de escolares da rede estadual da cidade de Florianópolis. Motriz, Rio Claro, v. 14, n. 4, p. 373-380, dez. 2008. Disponível em: www.periodicos.rc.biblioteca.unesp.br/index.php/motriz/article/view/2066/1941. Acesso em: 07 ago. 2019

COMTE, Auguste. Curso de Filosofia Positiva. In: COMTE, A. Os Pensadores. São Paulo: Abril Cultural, 1978.

COSTA, Luciene Henrique da; SANTOS, Marysol de Souza; GÓIS JUNIOR, Edivaldo. O discurso médico e a Educação Física nas escolas (Brasil, século XIX). Revista Brasileira de Educação Física e Esporte, v. 28, n. 2, p. 273-282, abr. 2014. Disponível em: http://www.scielo.br/scielo.php?pid=S180755092014000200273\&script=sci_abstract\&tlng=pt. Acesso em: 07 ago. 2019.

CUNHA JUNIOR, Carlos Fernando. Os exercícios gymnasticos no Collegio Imperial de Pedro Segundo (1841-1870). Revista Brasileira de Ciências do Esporte, Porto Alegre, v. 25, n. 1, p. 69-81, set. 2003. Disponível em:

http://revista.cbce.org.br/index.php/RBCE/article/view/174/183. Acesso em: 07 ago. 2019.

DARIDO, Suraya Cristina; RANGEL, Irene Conceição. (Coords.). Educação física na escola. Rio de Janeiro: Guanabara Koogan, 2005.

DARIDO, Suraya Cristina. A educação física na escola e o processo de formação dos não praticantes de atividade física. Revista Brasileira da Educação Física e Esporte, São Paulo, v. 18, n. 1, p. $61-80$, mar. 2004. Disponível em:

http://www.revistas.usp.br/rbefe/article/view/16551/18264. Acesso em: 08 ago. 2019.

DARIDO, Suraya Cristina. Educação física na escola: realidade, aspectos legais e possibilidades. In: Universidade Estadual Paulista. Caderno de formação: formação de professores didática geral. São Paulo: Cultura Acadêmica, v. 16, p. 21-33, 2012.

FERNANDES, Swand de Paula; MOURA, Samara Silva de; SILVA, Siomara Aparecida da. Coordenação motora de escolares do ensino fundamental: influência de um programa de intervenção. Journal of Physical Education, Maringá, v. 28, n. 1, p. 1-10, out. 2016. Disponível em: http://www.scielo.br/pdf/jpe/v28/2448-2455-jpe-28-e2842.pdf. Acesso em: 08 ago. 2019.

GATTI, Bernardete A. Formação de professores no Brasil: características e problemas. Educação \& Sociedade, Campinas, v. 31, n. 113, p. 1355-1379, dez. 2010. Disponível em: http://www.scielo.br/scielo.php?pid=s010173302010000400016\&script=sci_abstract\&tlng=pt. Acesso em: 08 ago. 2019.

GHIRALDELLI JÚNIOR, Paulo. Educação física progressista: a pedagogia crítico-social dos conteúdos e a educação física brasileira. São Paulo: Loyola, 1991. 
GOODWAY, Jacqueline; BRANTA, Crystal. Influence of a Motor Skill Intervention on Fundamental Motor Skill Development of Disadvantaged Preschool Children. Research Quarterly for Exercise and Sport, v. 74, n. 1, p. 36-46, 2003. Disponível em: https://www.tandfonline.com/doi/pdf/10.1080/02701367.2003.10609062

HALLAL, Pedro Curi.; MELO, Vitor Andrade. Crescendo e enfraquecendo: um olhar sobre os rumos da Educação Física no Brasil. Revista Brasileira de Ciências do Esporte, v. 39, n. 3, p. 322-327, 2017. Disponível em: http://www.rbceonline.org.br/es-crescendo-eenfraquecendo-um-olhar-articulo-S0101328916300087

HAYWOOD Kathleen; GETCHELL, Nancy. Desenvolvimento motor ao longo da vida. 3. ed. Porto Alegre: Artmed, p. 344, 2004. Disponível em:

https://acervodigital.ufpr.br/bitstream/handle/1884/25006/RICARDO\%20ALEXANDRE\%2 OCARMINATO $\% 20 \% 20$ DESEMPENHO $\% 20$ MOTOR $\% 20$ DE $\% 20$ ESCOLARES $\% 20 A T R A V E S \%$ 20DA\%20BATERIA\%20DE\%20TESTE\%20KTK\%20-

$\% 20201$. pdf?sequence $=1$ \&isAllowed $=y$

KIPHARD, E. J.; SCHILLING, V. F. Köperkoordinationstest Für Kinder KTK: manual Von Fridhelm Schilling. Weinheim: Beltz Test Gmbh., 1974.

KHUM, Thomas. A estrutura das revoluções científicas. São Paulo: Editora Perspectiva S.A, 2006.

KIPHARD, E. J.; SCHILLING, V. F. Köperkoordinationstest Für Kinder KTK: manual Von Fridhelm Schilling. Weinheim: Beltz Test Gmbh., 1974.

LIBÂNEO, José Carlos. Didática. São Paulo: Cortez, 1994.

LOPES, Marcia Regina Sousa; MILLEN NETO, Álvaro Rego; PARENTE, Maria Larissy da Cruz; ARAÚJO, João Gabriel Eugênio; SOUSA, Cleyton Batista de; MOURA, Diego Luz. A prática do planejamento educacional em professores de educação física: construindo uma cultura do planejamento. Journal of Physical Education, Maringá, v. 27, n. 1, p. 1-9, mar. 2017. Disponível em:

http://www.scielo.br/scielo.php?pid=S24484552016000100144\&script=sci abstract\&tIng =pt. Acesso em: 08 ago. 2019.

LUCKESI, Cipriano Carlos. O que é mesmo o ato de avaliar a aprendizagem. Revista Pátio, São Paulo, v. 12, n. 3, p. 6-15, abr. 2000.

LUDKE, Menga; ANDRÉ, Marly. E. D. Pesquisa em educação: abordagens qualitativas: temas básicos de educação e ensino. São Paulo, 1986.

MAIA, José Antonio Ribeiro; LOPES, Vitor. Crescimento e desenvolvimento de crianças e jovens Açorianos. O que pais, professores, pediatras e nutricionistas gostariam de saber. Porto: Saudaçor S.A., 2007. Disponível em:

https://bibliotecadigital.ipb.pt/bitstream/10198/2721/1/CRESCIMENTO-

DESENVOLVIMENTO Açores2007.pdf. Acesso em: 08 ago. 2019.

MAIA, José A. Método clínico e paradigmas da ciência. Interface - Comunicação, Saúde, Educação, Botucatu, v. 4, n. 6, p. 177-179, fev. 2000. Disponível em:

http://www.scielo.br/scielo.php?script=sci arttext\&pid=S1414-32832000000100024.

Acesso em: 08 ago. 2019.

MALDONADO, Daniel Teixeira; LIMONGELLI, Ana Martha de Almeida. Educação física no ensino fundamental: prática pedagógica e formação acadêmica. Educação Física em Revista, Brasília, v. 8, n. 1, p. 23-33, jul. 2014. Disponível em: https://portalrevistas.ucb.br/index.php/efr/article/view/4880/3422. Acesso em: 08 ago. 2019. 
MALDONADO, Daniel Teixeira; SILVA, Sheila Aparecida Pereira dos Santos.

Fundamentação teórica da educação física em propostas curriculares da escola pública de São Paulo: uma análise das abordagens pedagógicas. Educação em Revista, Belo Horizonte, v. 34, p. 1-20, out. 2018. Disponível em:

http://www.scielo.br/scielo.php?script=sci arttext\&pid=S010246982018000100180\&lng $=$ pt\&nrm=iso\&tlng=pt. Acesso em: 08 ago. 2019.

MANOEL, Edison de Jesus. Desenvolvimento motor: implicações para a Educação Física escolar I. Revista Paulista de Educação Física, São Paulo, v. 8, n. 1, p. 82-97, jun. 1994. Disponível em: http://www.revistas.usp.br/rpef/article/view/138423. Acesso em: 08 ago. 2019.

MARX, Karl. Prefácio à "Contribuição à crítica da economia política" de Karl Marx. In MARX, Karl; ENGELS, Friedrich. Textos. São Paulo: Editora Alfa-Omega, 1975. v. III.

MINAYO, Maria C. S. (Org.). Pesquisa social: teoria, método e criatividade. Rio de Janeiro: Vozes, 2001.

NASCIMENTO, Flávia Marchi; SANTOS, Leontine Lima dos; ANDRADE, Daniélle Lima de; MONTIEL, Fabiana Celente; AFONSO, Mariângela da Rosa; CHIVIACOWSKY, Suzete. Saberes mobilizados no desenvolvimento das habilidades motoras básicas na educação física escolar. Revista Didática Sistêmica, Rio Grande, v. 11, n. 1, p. 234-246, jul. 2011. Disponível em: https://periodicos.furg.br/redsis/article/view/1758/945. Acesso em: 08 ago. 2019.

NEGRINE, Airton; GAUER, Ruth. Educação física e desporto: uma visão pedagógica e antropológica. Porto Alegre: Posenato Arte \& Cultura, 1990.

OLIVEIRA, V. N. O que é educação física? Coleção primeiros passos. São Paulo: Brasiliense, 2004.

PAIVA, Fernanda Simone Lopes de. Contribuições da Hygiene à escolarização da Educação Física. Movimento, Porto Alegre, v. 10, n. 3, p. 53-75, dez. 2007. Disponível em: https://seer.ufrgs.br/Movimento/article/view/2849. Acesso em: 08 ago. 2019.

PELOZIN, Fernanda; FOLLE, Alexandre; COLLET, Carine; BOTTI, Marise, NASCIMENTO, Juarez Vieira do. Nível de Coordenação Motora de Escolares de 09 da11 Anos da Rede Estadual de Ensino da Cidade de Florianópolis/Sc. Revista Mackenzie de Educação Física e Esporte, São Paulo, v. 8, n. 2, p. 123-132, dez. 2009. Disponível em: http://editorarevistas.mackenzie.br/index.php/remef/article/view/1882/1360. Acesso em: 08 ago. 2019.

PEREIRA, Ana Maria; CESÁRIO, Marilene. A ginástica nas aulas de Educação Física: o "aquecimento corporal" em questão. Revista da Educação Física/UEM, Maringá, v. 22, n. 4, p. 637-649, 4 dez. 2011. Disponível em:

http://www.periodicos.uem.br/ojs/index.php/RevEducFis/article/view/12536/8662. Acesso em: 08 ago. 2019.

PEREIRA, Fabiana. O Que Revela O Último Decênio (2008-2018) De Produção Científica Sobre Avaliação Na Educação Física Escolar? 2019. Trabalho de Conclusão de Curso (Licenciatura em Educação Física) - Departamento Educação Física, Universidade Federal de Lavras, Lavras/MG, 2019.

RINALDI, Ieda Parra Barbosa. A ginástica como área de conhecimento na formação profissional em Educação Física: encaminhamentos para uma estruturação curricular. 2004. Tese (Doutorado em Educação Física) - Faculdade de Educação Física, Universidade Estadual de Campinas, Campinas, 2004. Disponível em: http://repositorio.unicamp.br/bitstream/REPOSIP/274939/1/Rinaldi_IedaParraBarbosa_D .pdf. Acesso em: 9 ago. 2019. 
RODRIGUES, Heitor de Andrade; DARIDO, Suraya Cristina. A técnica esportiva em aulas de educação física: um olhar sobre as tendências sócio-culturais. Movimento, Porto Alegre, v. 14, n. 2, p. 137-154, 4 set. 2008. Disponível em: https://seer.ufrgs.br/Movimento/article/view/2549. Acesso em: 9 ago. 2019.

SILVA, Maria Cecília de Paula. A educação física escolar/saúde: o discurso médico no século XIX. Revista Brasileira de Ciências do Esporte, v. 25, n. 2, p. 97-112, jan. 2004. Disponível em:

http://oldarchive.rbceonline.org.br/index.php/RBCE/article/viewFile/229/231. Acesso em: 09 ago. 2004.

SOARES, C. L. Educação física, raízes européias e Brasil. 3. ed. Campinas: Autores Associados, 2004.

STIEG, Ronildo; VIEIRA, Aline de Oliveira; FROSSARD, Matheus Lima; NETO, Amarílio Ferreira; SANTOS, Wagner dos. Avaliação educacional nos cursos de licenciatura em educação física nas IES brasileiras: uma análise das disciplinas específicas. Currículo Sem Fronteiras, Vitória, v. 18, n. 2, p. 639-667, ago. 2018. Disponível em:

http://www.curriculosemfronteiras.org/vol18iss2articles/stieg-etall.pdf. Acesso em: 09 ago. 2019.

TANI, Go; BASSO, Luciano; SILVEIRA, Sérgio Roberto; CORREIA, Walter Roberto; CORRÊA, Umberto Cesar. O ensino de habilidades motoras esportivas na escola e o esporte de alto rendimento: discurso, realidade e possibilidades. Revista Brasileira de Educação Física e Esporte, v. 27, n. 3, p. 507-518, set. 2013. Disponível em: http://www.scielo.br/scielo.php?pid=S180755092013000300016\&script=sci abstract\&tlng=pt. Acesso em: 09 ago. 2019.

TANI, Go; MANOEL, Edison de Jesus.; KOKUBUM, Eduardo; PROENÇA, José Elias. Educação Física Escolar: Fundamentos de uma abordagem desenvolvimentista. São Paulo: Editora EPU, 1988.

TANI, Go. Abordagem desenvolvimentista: 20 anos depois. Revista da Educação Física/UEM, Maringá, v. 19, n. 3, p. 313-331, 15 dez. 2008. Disponível em: http://www.periodicos.uem.br/ojs/index.php/RevEducFis/article/view/5022. Acesso em: 09 ago. 2019.

ULRICH, Dale. The test of gross motor development. 2. ed. Austin: Prod-Ed, 2000.

VALDIVIA, Alcibiades Bustamante; CARTAGENA, Liz Caballero; SARRIA, Natalia Enciso; TÁVARA, Ingrid Salazar; SEABRA, André F. Teixeira; SILVA, Rui Manuel Garganta da; MAIA, José Antonio Ribeiro. Coordinación motora: influencia de la edad, sexo, estatus socioeconómico y niveles de adiposidad en niños peruanos. Revista Brasileira de Cineantropometria e Desempenho Humano, Florianópolis, v. 10, n. 1, p. 25-34, 2008. Disponível em: https://periodicos.ufsc.br/index.php/rbcdh/article/view/19800037.2008v10n1p25. Acesso em: 09 ago. 2019. assim, a integridade dos artigos em ambiente de acesso aberto. 
A Revista Conexões é integrante do Portal de Periódicos Eletrônicos da Unicamp e associado/membro das seguintes instituições:

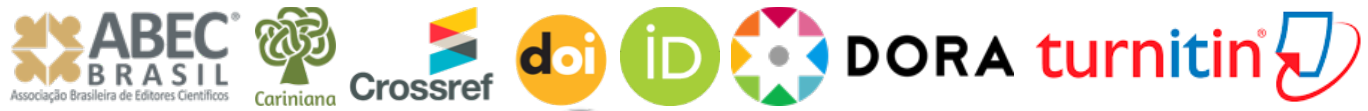

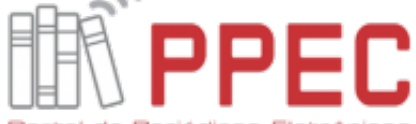

Portal de Periodicos Eletronico

Cientificos de UNICAMP 